University of Wollongong

Research Online

Faculty of Social Sciences - Papers (Archive) Faculty of Arts, Social Sciences \& Humanities

2017

Transformative travel as a sustainable market niche for protected areas: a new development, marketing and conservation model

Isabelle D. Wolf

University of Wollongong, iwolf@uow.edu.au

Gillian Ainsworth

Charles Darwin University

Jane Crowley

Macquarie University

Follow this and additional works at: https://ro.uow.edu.au/sspapers

Part of the Education Commons, and the Social and Behavioral Sciences Commons

Research Online is the open access institutional repository for the University of Wollongong. For further information contact the UOW Library: research-pubs@uow.edu.au 


\title{
Transformative travel as a sustainable market niche for protected areas: a new development, marketing and conservation model
}

\author{
Abstract \\ Many protected areas worldwide are mandated to provide visitor enjoyment and sustainable heritage \\ conservation but face growing challenges and competition. To satisfy modern aspirational markets, parks \\ must design meaningful experiences delivering long-lasting participant benefits that cultivate visitation \\ rates and a conservation constituency. Transformative travel can deliver such benefits through \\ participants' psycho-physiological transformation but market insights critical for experience development \\ in parks are lacking. Our systematic quantitative review of 126 transformative travel articles provides \\ those insights, linking experiential characteristics, participant traits and motivations to experience \\ outcomes according to five transformative travel typologies pertinent to parks: health and wellness, \\ nature-based physical activity, spiritual, cultural and volunteering travel. We identified 35 travel \\ motivations, 14 participant traits and 23 experience characteristics linked to transformation and 28 \\ purposefully or incidentally realised benefits. Transformative travel improved participants' psychological, \\ physiological, social, economic and environmental conditions, as well as satisfaction with and destination \\ loyalty towards parks. Socio-demographic characteristics and propensity for independent versus social \\ travel shaped choice of travel experience. Our results are uniquely conceptualised in a transformative \\ travel framework and transformative market niche model which we apply to sustainable experience \\ development and marketing in parks. We identify implementation possibilities and areas for future \\ research and monitoring.

\section{Keywords} \\ model, market, conservation, sustainable, travel, transformative, marketing, development, areas:, \\ protected, niche

\section{Disciplines} \\ Education | Social and Behavioral Sciences

\section{Publication Details} \\ Wolf, I. D., Ainsworth, G. B. \& Crowley, J. (2017). Transformative travel as a sustainable market niche for \\ protected areas: a new development, marketing and conservation model. Journal of Sustainable Tourism, \\ 25 (11), 1650-1673.
}

This journal article is available at Research Online: https://ro.uow.edu.au/sspapers/4521 


\title{
Transformative Travel as a Sustainable Market Niche for Protected Areas: a new Development, Marketing and Conservation Model
}

\author{
Isabelle D. WOLF ${ }^{\mathrm{a}, \mathrm{b},{ }^{*}, \text { Gillian B. AINSWORTH }{ }^{\mathrm{c}, \mathrm{d}} \text {, Jane CROWLEY }}{ }^{\mathrm{e}}$ \\ ${ }^{a}$ NSW National Parks and Wildlife Service, Office of Environment and Heritage, Department \\ of Premier and Cabinet, Hurstville, NSW 2220, Australia \\ ${ }^{b}$ Centre for Ecosystem Science, University of New South Wales, Sydney, NSW 2052, Australia \\ ${ }^{c}$ Research Institute for Environment and Livelihoods, Charles Darwin University, Darwin, \\ NT 0909, Australia \\ ${ }^{d}$ School of Biological Sciences, University of Aberdeen, Aberdeen, AB24 2TZ, United \\ Kingdom \\ ${ }^{e}$ Department of Environmental Sciences, Macquarie University, Sydney, NSW 2109, Australia
}

*Corresponding author: i.wolf@online.ms, Office of Environment and Heritage, Department of Premier and Cabinet, Bridge Street 43, Hurstville, NSW 2220, Australia Tel.: +61 40330 3550, Fax: +61 295856601 .

Email for each author: i.wolf@online.ms; g.ainsworth@abdn.ac.uk; jane.crowley@students.mq.edu.au

Phone number for each author: +61 40330 3550; +61 88988 2047; +61 423870847

Dr. Isabelle Wolf is a protected areas specialist conducting research and enhancing methods for park visitor monitoring, sustainable visitor experience development and management. She is leading GISrelated visitor monitoring projects. Trained as an ecologist, her speciality are the human dimensions of ecosystems, with recent work on animal behaviour and flora and fauna communities in fragmented and disturbed habitats. Isabelle has a PhD degree from the University of New South Wales and has published in both social and environmental science journals.

Dr. Gillian Ainsworth, Honorary Research Fellow, Research Institute for Environment and Livelihoods, Charles Darwin University, Australia. Her PhD examined how social values may influence conservation of Australian threatened birds. Current research interests include the relationships between humans and nature and the conservation of threatened species.

Jane Crowley is a Post-Graduate Environment student at Macquarie University, following a Degree in Social Sciences at UNSW. She has worked in marketing and communications and environmental research, now running a project on engaging youth into nature for Macquarie University. Jane is also writing a children’s book to shift the fearful perceptions of nature. 


\section{Abstract}

Many protected areas worldwide are mandated to provide visitor enjoyment and sustainable heritage conservation but face growing challenges and competition. To satisfy modern aspirational markets, parks must design meaningful experiences delivering longlasting participant benefits that cultivate visitation rates and a conservation constituency. Transformative travel can deliver such benefits through participants’ psycho-physiological transformation but market insights critical for experience development in parks are lacking. Our systematic quantitative review of 126 transformative travel articles provides those insights, linking experiential characteristics, participant traits and motivations to experience outcomes according to five transformative travel typologies pertinent to parks: health and wellness, nature-based physical activity, spiritual, cultural and volunteering travel. We identified 35 travel motivations, 14 participant traits and 23 experience characteristics linked to transformation and 28 purposefully or incidentally realised benefits. Transformative travel improved participants’ psychological, physiological, social, economic and environmental conditions as well as satisfaction with and destination loyalty towards parks. Sociodemographic characteristics and propensity for independent versus social travel shaped choice of travel experience. Our results are uniquely conceptualised in a transformative travel framework and transformative market niche model which we apply to sustainable experience development and marketing in parks. We identify implementation possibilities and areas for future research and monitoring.

Key words: transformation; benefit; visitor experience; nature; park; market. 


\section{Introduction}

Many protected areas (parks) worldwide have a dual mandate of conserving natural areas and providing experiences to the visiting community. Although urban and rural parks can provide valuable multifunctional, health-promoting spaces where people may conduct various nature-based activities ranging from contemplation to sports and species conservation, many people do not visit parks or participate in such activities due to various physical and social barriers (Pretty et al., 2007). Enhancing park visitor experiences is not only essential to attract visitors (Weiler, Moore, \& Moyle, 2013) but also to build a constituency for park conservation (Eagles \& McCool, 2002), and to support the measurement of park relevance and value in an increasingly neo-liberal era (Whitelaw, King, \& Tolkach, 2014). However, these efforts are currently challenged by the lack of appreciation of visitation and community benefits that parks can provide (Buckley, 2009; Eagles \& McCool, 2002), a lack of research highlighting these benefits (Uysal, Sirgy, Woo, \& Kim, 2016) and a lack of opportunities for visitors to experience the full spectrum of benefits (Weiler et al., 2013).

For many years visitation to protected areas rose steadily but at the beginning of the twenty-first century growth faltered. Schwartz and Lin (2006) ascribed some of that phenomenon in the USA to the introduction of entrance fees. But competition was also important, including increasing visits to overseas tourism destinations, and to attractions like wildlife parks and zoos, theme parks and commercial tours (Pergams \& Zaradic, 2008; Weiler et al., 2013). Meanwhile, customer expectations are increasing as travellers shift their discretionary income away from material products towards more personalised and authentic experiences (Hajkowicz, Cook, \& Boughen, 2013). People are sourcing greater clarity and personal meaning in private, spiritual, work or consumption contexts due to increasing pressures and societal complexities associated with living in the twenty-first century (Dwyer et al., 2008). In such an "experience economy" people seek experiences above any other 
material product (Pine \& Gilmore, 1999), valuing the experience as "always more than just the product" (Sundbo \& Darmer, 2008, p. 1).

To be successful in the face of such challenges parks must develop accessible, satisfying, novel and meaningful visitor experiences providing long-lasting benefits to participants, while at the same time ensuring that the conservation of biodiversity, landscapes, cultural character and local economies are fostered. So-called transformative travel experiences hold great potential to add value to the visitor experience portfolio in parks, partly because they include responsible and sustainable practices guided by values of respect for hosts and ecosystems (Ross 2010).

Transformative travel is a recent and noteworthy development within tourism and recreation, and encompasses the two dimensions of transformation and travel. The transformational process enables an individual to become "someone" different and requires a positive change in "attitude, performance, characteristics or some other fundamental personal dimension” (Pine \& Gilmore 1999, cited in Gelter, 2010, p. 48). Transformation is therefore considered a personal growth-enhancing and developmental change with potentially wide societal implications (Merriam \& Caffarella, 1999; Saunders, Laing, \& Weiler, 2014). Travel was viewed as an agent of transformation as it features most of the conditions (e.g. novelty) leading to individual and societal change, due to increased personal awareness, empathy and development of new values (Kottler, 1998; see review by Lean, 2009; Leed, 1991; Reisinger, 2013c). Transformation as an outcome of integrating experiential elements in travel was seen as the ultimate form of an experience (Pine \& Gilmore, 1999). Although the transformative power of travel has long been noted, transformative travel as a concept is a comparatively recent term, popularised by Kottler (1997) in the context of therapeutic travel. Christie and Mason (2003, p. 9) speak of transformative tourism as one "that leads to a positive change in attitudes and values". Ross (2010, p. 55) defines transformative travel as "sustainable travel 
embarked upon by the traveller for the primary and intentional purpose of creating conditions conducive for one or more fundamental structures of the self to transform". This emphasises the traveller’s deliberate intention to transform. However, others (Kottler, 2002; Kottler \& Montgomery, 2000; Lean, 2005; Roberson, 2002) do not associate intention with transformation as the latter can be experienced without planning or anticipation, and in almost any context for those ready to change (Reisinger, 2013a). Saunders, Laing and Weiler (2014) argue that this change can be subtle and often unintentional, with varied drivers ranging from having novel experiences to experiencing mindfulness and deep processing through immersion. Kottler (2002) suggests that transformation is a natural result of requiring new ways of problem solving, encountering new stimuli, developing relationships, experiencing new cultures or dismantling of core beliefs. Similarly, Roberson (2002) suggests transformation occurs incidentally on gaining new perspectives from other cultures or from reading about a destination before or after a trip.

Transformative travel has long had connections to sustainable tourism, and those connections are growing. The pioneers of the sustainable tourism concept in the 1980s sought more responsive, thoughtful and mind expanding travel possibilities (see for example Krippendorf, 1988, pp 66-68). Their ideas about that form of travel were in outline at best and little developed either by researchers or in practice until recently. The first major researcher group to begin to, almost accidentally, explore transformative travel was linked to the search for behavioural change in travel to reduce tourism's impacts on climate change (Higham, Cohen, Peeters, \& Gössling, 2013, part of a Special Journal Issue on behavioural change in travel).

This study moves the research focus to reviewing the potential for providing transformative travel experiences in parks, and applied the broader definition of personal change accrued purposefully, where one intentionally seeks change; and incidentally, where 
unintended change occurs consequentially. This review, therefore, encompasses the full spectrum of what is commonly referred to as the "park benefits literature" (e.g. Moyle, Weiler, \& Moore, 2014; Torland, Weiler, Moyle, \& Wolf, 2015). Intentional transformative experiences in parks could include nature walks that attract those specifically seeking relaxation or improved physical health; however, these transformations may also be incidental in those who participated for other reasons such as socialising or sightseeing. In fact visitors may not always realise how beneficial park experiences are until they participate in them (Wolf \& Wohlfart, 2014).

Parks provide ideal settings for people to transform both purposefully and incidentally. There, the human experience is developed from being in a non-human environment as visitors gain a new appreciation of its beauty and are surrounded by a variety of stimuli that may drive self-exploration, critical reflection, learning and thus transformation. From witnessing natural wonders, individuals "become humble before forces greater than them or beyond their control" (Reisinger, 2013b, p. 29). Parks embody relevant properties like efficacy, power, spirit of place and existential values that foster transformation and can lead to moral development (Morgan, 2010a). Further to improving overall quality of life from increased physical and mental health, parks in particular provide opportunities for intimately connecting with culture, heritage, family and spirituality (Moyle et al., 2014; Sharpley \& Jepson, 2015). All can trigger the process of transformation which, according to Mezirow (1991, 2012), the founder of the transformative learning theory, begins with an individual experiencing a disorienting dilemma requiring reflection and a strategy for resolution. The individual then undergoes a period of self-examination and critical assessment to design and implement this new strategy. In this process, the individual develops new skills, attitudes, beliefs, opinions and emotional reactions, and self-confidence; ultimately undergoing transformation. Pomfret (2012) describes such changes as personal emotional journeys in 
adventure activities during packaged mountaineering holidays. While travelling in parks, a dilemma is likely to occur because of being in unfamiliar places, and among foreign cultures reminiscent of Reisinger's (2013c, p .28) observation that "transformation takes place in places that broaden the horizon or change a mindset;.. that present individuals with a different experience to their habitual domestic environment". Thus, transformative visitor experiences in parks should be particularly effective as the generally transformative power of travel fuses with the transformative power of natural, awe-inspiring environments (Pearce, StricklandMunro, \& Moore, 2017).

Transformations following nature-based travel experiences in parks are manifold (Manning, 1999). Psycho-physiological benefits, for example from visiting parks, relate to reduced risk of heart attack, stress, depression and other mental disorders and increased cardiovascular fitness (Kaplan \& Kaplan, 1989; Wolf \& Wohlfart, 2014). Social benefits include strengthened family networks, community cohesion and social capital (Hewlett \& Edwards, 2013; Sugiyama, Leslie, Giles-Corti, \& Owen, 2008); economic benefits can be personal but also involve improved business and investment surrounding parks, and environmental benefits relate to changed attitudes and behaviours, and the protection of natural assets (Buckley, 2009; Driver, 2008a; Leslie; Moyle et al., 2014).

Transformative travel can benefit both participants and experience providers by increasing park visitors’ appreciation for parks through attained benefits, thereby increasing visitor numbers, word-of-mouth recommendations and repeat visitation (Sharpley \& Jepson, 2015; Wolf, Stricker, \& Hagenloh, 2015), further linked to place attachment (Graefe, Thapa, Confer, \& Absher, 2000; Kelly \& Smith, 2009; López-Mosquera \& Sánchez, 2013; Sharpley \& Jepson, 2015), and increased visitor expenditure (Barton, Hine, \& Pretty, 2009; Damijanić \& Šergo, 2013). The challenge for parks is to provide visitor experiences that encourage connection to parks, leading to shared appreciation and stewardship for parks (López- 
Mosquera \& Sánchez, 2013). Park promotion and packaging as venues influences the meanings derived from park experiences, and how often and in what capacity people engage with and support the preservation of parks. A critical research priority in park tourism involves investigating which programmes have meaning and therefore create public support for parks (Eagles, 2014).

Daengbuppha, Hemmington, \& Wilkes (2006) and Williams (2006) noted the lack of indepth research on visitor experiences, as opposed to product consumption, that would be necessary for a deeper understanding of the interaction between visitors and attractions, the meaning of the experience for the visitor (Daengbuppha et al., 2006), and for the preparation of effective marketing strategies (Morgan \& Watson, 2009). Driver (2008a) was subsequently instrumental in inspiring research on the experience-outcome relationship in parks. Driver's (2008a) Outcomes-Focused Management (OFM) can be used as a tourism and recreation tool to determine benefits, also referred to as outcomes, transformations, positive changes or improvements that experience providers wish to offer to their customers. OFM suggests that participants in adequately designed and marketed tourism and recreation activities accrue benefits that last beyond the experience. However, few (e.g. Tucker, Allen, \& Driver, 2008; Wolf et al., 2015) have applied Driver's work to conceptualise the relationship between experiential traits and participant outcomes. Our study employed OFM as a conceptual framework to identify the benefits available to travellers partaking in nature-based transformative travel; it fills an important research gap by linking specific experiential traits to outcomes for participants and experience providers while considering market characteristics and motivations which can guide experience design, marketing, monitoring and communication of success. Ross (2010) highlights the importance of this type of research in that many studies have evidenced transformation accrued from travelling but few have examined specific elements of travel that contribute to the transformative experience. OFM 
was applied to the full spectrum of travel experiences on a continuum ranging from recreational activity to tourism experiences acknowledging that distinguishing tourism from recreation has been found impractical for park management purposes (Manning, 1999).

The systematic quantitative literature review below (Pickering \& Byrne, 2014) focused on five travel typologies known for their transformative power to be harnessed in a visitorcentric and outcome-focused park management context (Reisinger, 2013c; Ross, 2010): (1) health and wellness (wellbeing) travel including (2) nature-based physical activity (nbPA); (3) spiritual travel; (4) cultural travel; and (5) volunteering/voluntourism. Overlaps may exist for example if volunteering activities integrate health and wellness aspects. "Parks" encompassed a broad range of protected areas and public green spaces with results being relevant to national parks, nature reserves, public gardens and recreation areas alike.

Health and wellness travel was defined as a "holistic mode of travel that integrates a quest for physical health, beauty, or longevity, and/or a heightening of consciousness or spiritual awareness, and a connection with community, nature, or the divine mystery" (Bushell \& Sheldon, 2009a, p. 11). To qualify as a contemporary health and wellness travel experience, some deliberate contribution is made to psychological, spiritual or emotional wellbeing in addition to physical wellbeing, satisfying those seeking reconciliation of body, mind and spirit (Smith \& Kelly, 2006b). Health and wellness travel ranges from consuming luxury spa products to meditating in an ashram ${ }^{\mathrm{i}}$ or undertaking physical outdoor adventures. Medical tourism is associated with health and wellness travel (Voigt \& Pforr, 2013) but was not part of our review. Health and wellness travel is often staged in natural environments conducive to people's wellbeing. Nature-based outdoor travel/nbPA were reviewed as a subcategory of health and wellness travel where physical activity is the focus.

Transformative spiritual travel is where one embarks on a personal journey for selfreflection. Willson (2008, p. 6) suggests, spirituality is the "essence of being human that 
involves a personal and often-transcendent quest for meaning, purpose, and connectedness (with self/others and/or God). One's spirituality is manifested through one's values, morals, ethics and actions, and is at the core of one's well-being". Therefore, representing the essence of humanity regardless of cast, creed or religion, spirituality is a much broader concept than religion (Willson, 2008). Since travel provides the time and space for self-reflection, transformative spiritual experiences may occur in nearly every travel situation, even the most mundane contexts (Willson, 2008). Natural settings however provide ideal backdrops.

Transformative cultural travellers are driven to discover their own society and self, including their inadequacies and competencies (Ross, 2010). Experiencing different cultural customs, values and attitudes can happen between different countries, within the same country between rural and urban environments, and between Indigenous and non-Indigenous cultures. This can be likened to the disorienting dilemma triggering the transformative process, otherwise known as culture shock, and provides a platform for self-evaluation. Cultural histories and traditions are shared through visitor experiences like cultural events, walks and camps. Authentic Indigenous experiences help inspire and educate park visitors by revealing cultural histories behind natural areas, leading to more direct interactions with Indigenous populations, potentially transforming relationships (Richards \& Wilson, 2006).

Volunteering travel includes a diverse field and is defined as "an un-coerced and nonremunerated helping activity" (Caissie \& Halpenny, 2003, p. 39), where one freely offers time, skills and experience to benefit a community or its surrounding natural environment. Voluntourism involves volunteering abroad where individuals "undertake holidays that might involve aiding or alleviating the material poverty of some groups in society, the restoration of certain environments or research into aspects of society or environment" (Wearing, 2001, p. 184). Volunteering and voluntourism can potentially transform people and their environments (Brightsmith, Stronza, \& Holle, 2008), deliver cultural benefits related to cross-cultural 
understanding (Raymond \& Hall, 2008), and socio-economic benefits such as poverty alleviation and social justice (Stoddart \& Rogerson, 2004). Many parks offer nature and heritage conservation volunteer programmes where people can participate to fulfil these motivations and benefits.

Three main questions were asked in this systematic quantitative review: (1) who are the transformative travellers and what are their motivations; (2) which benefits can be realised from transformative travel; and (3) which experiential traits drive transformation. Findings were integrated in a broader framework of transformative travel linking experience traits with outcomes for participants and experience providers in parks, and a finer-scale model summarising the key quantitative results of this review. In a systematic quantitative literature review (Pickering \& Byrne, 2014) the focus is on a numeric quantification of publications dedicated to the topics under investigation, in contrast to the in-depth narration of results as typical for a narrative review. This literature mapping-type approach was deemed particularly useful for emerging fields of research. So far systematic quantitative literature reviews have more commonly been applied in the environmental sciences or in interdisciplinary studies but they open up new avenues for a systematic investigation of publications in the social sciences to produce a structured quantitative summary of the field. This research demonstrates how quantitative review insights captured in a conceptual model will be useful for park management, and park-based businesses, to design, market and monitor transformative travel experiences, and highlights future research needs.

\section{Methods}

We used a systematic, quantitative methodology to review relevant literature, quantify results and identify key gaps (Pickering \& Byrne, 2014). Articles were sourced about transformative travel from highly regarded, comprehensive online electronic databases for 
academic research, primarily Google Scholar and Web of Science (Pickering \& Byrne, 2014; van Aalst, 2010).

Keywords and combinations thereof were identified and searched for. To determine the general context we used: travel, tourism, recreation, (visitor) experience, (national) park, outdoors, nature. To capture literature that describes potential benefits to participants in accordance with Driver's (2008a) definitions we used: transformation, transform, transformative, transformational, outcome, benefit, improvement, (positive) change. These were coupled with 12 keywords representing the five transformative travel typologies: wellness, wellbeing, health, nature-based physical activity, spiritual, cultural, indigenous, volunteer, voluntourist, voluntourism, volunteering. Articles were reviewed for suitability and were included if they explored purposeful or incidental transformation resulting from experiences in one of the five typologies. We specifically ensured articles were relevant for visitor experience development in protected areas, limiting the review to studies examining travel experiences deemed directly transferrable to urban or rural national parks, nature reserves, public gardens or recreation areas.

We excluded articles which featured the general benefits of transformative travel or taking holidays; focused on social, medical, spa or religious tourism; did not specifically examine tourism experiences (e.g. branding or communication studies); or were not directly linked to our five typologies; and most that were purely conceptual.

Research published in academic English language journals in the past 15 years was reviewed. Article citation lists and other resources were examined to trace additional papers, and research not available electronically such as books (with a main focus on recent groundbreaking works of Bushell \& Sheldon, 2009b; Filep \& Pearce, 2013; Reisinger, 2013c; Smith \& Puczkó, 2014; Voigt \& Pforr, 2013). 
The socio-demographic characteristics of transformative travellers were recorded according to what the reviewed papers reported regarding age, gender bias, and socioeconomic background. Some latent segments of the potential market had not been previously researched and are, therefore, not well represented in the reviewed publications. Our results are therefore restricted to the market characteristics which were reviewed; making recommendations for monitoring or experience design relating to "the market in general" is beyond the scope of this study.

Also recorded were study participants' traits linked to transformation (e.g. adaptability, open mindedness) and reported motivations for participating in transformative travel, broadly categorised as follows: travel/escape, new experiences, nature/scenery, exploration, health/fitness or wellbeing, relaxation, stress reduction, social networking, risk or challenge, enjoyment/excitement; personal or professional development, or new skills; cultural, religious or spiritual enlightenment; independent or social experiences; authentic or humanitarian experiences; guest-host interaction; and willingness to pay for experiences.

Articles were analysed in accordance with Driver’s (2008a) OFM framework to identify potential outcomes/benefits of transformative travel; that is, whether travel experiences improved or maintained wanted, or prevented and reduced unwanted, psychological, physiological, social, economic or environmental conditions. Driver’s (2008b) list of outcomes guided the initial selection of benefits included for review, and was further defined in the dynamic process described below and categorised as health and well-being (physical, psychological, emotional, spiritual); sociocultural and personal relationship building (social, cultural, good citizenship, solidarity/teamwork, recognition of relationships); personal competence (self-enrichment, independence, career/personal skills); environmental (appreciation for, awareness/sensitivity, support for conservation); economic; as well as sense of achievement, regular/repeated participation, and encouraging others to 
participate/transform. Also noted was whether benefits were reported as being incidental or purposeful, short or long term; and behavioural in terms of donating time or money, adopting sustainable lifestyles, purchasing, political action, level of responsibility or involvement.

Experience characteristics that facilitate transformation were recorded in five main categories: environmental context of the travel experience (natural, rural, urban, foreign); reconnection (with oneself, land/heritage, family); immersion (generally immersive, participatory, social, cultural, active, combination of active and passive elements, interactive); general activity parameters (offers escape, opportunity for repeat/regular/prolonged participation, authenticity, adopts ecotourism principles, incorporates a gastronomic experience); and type of challenge (mental, emotional, physical, environmental).

Topic categories and subcategories of variables describing motivations, benefits and facilitating experience characteristics were initially identified based on a review of key publications, previous research experience of the lead author in park benefit research and informal discussion between researchers and national park agency staff with expertise in visitor experience development and interpretation. These categories were piloted and subsequently refined by aggregating, subdividing and adding categories for comprehensiveness, etc. (Pickering \& Byrne, 2014). Further minor modifications were applied to categories, or new categories were added, while entering the bulk of literature where appropriate. A database was developed where each publication was assigned to a single row with topics as columns and their presence/absence coded. This enabled production of summary tables to enumerate the number and percentage of publications dedicated to the topic(s) under investigation. Unless stated otherwise the results presented are percentages (numbers) of all publications reviewed within a travel typology. That is, we provide a detailed breakdown of key characteristics by calculating the percentage of articles reporting 
each characteristic within a typology. For example, 15 of the 35 articles (43\%) reviewed in the spiritual typology category reported that participants were aged 18 or under (Table 1 ). In a few specified cases, we have calculated the percentage of all reviewed publications, pooled across all travel typologies. Results are presented descriptively throughout to reveal patterns in the literature and provide advice for researchers on future research avenues and for park managers on the application of the results for experience development, marketing, communication and monitoring.

\section{Results and discussion}

Although the personal, social and environmental benefits of nature-based tourism and recreation have been studied for over 40 years (Driver, 2008a; Manning, 1999), interest in transformative travel mainly developed within the last two decades with $46 \%$ of our reviewed studies published since 2010. Almost half (40\%) of the studies were located in Europe and published within journals or books about tourism and hospitality, tourism management, tourism marketing, health and tourism, hospitality and leisure, sustainable tourism and education.

We sourced 28 articles featuring health and wellness experiences. A further 27 articles on outdoor travel were reviewed as a subcategory of health and wellness travel where the focus was nature-based physical activity (nbPA), including outdoor education, green exercise, longdistance walking, climbing and white-water rafting. "Nature-based physical activity" and "outdoor recreation" were used synonymously in the literature and included wilderness and adventure recreation which involve risk taking, overcoming challenges and skill or character development. Eighteen articles dealt with transformative spiritual travel, including: spiritual retreats, lifestyle resorts and spas (Voigt, Brown, \& Howat, 2011); leisure and recreation; pilgrimages (if relevant for long-distance hiking); cultural and social heritage; ecotourism and sustainable tourism; education; and outdoor yoga and meditation. Literature on spas was 
excluded unless findings related to park visitor experience development. It may prove fruitful for parks to more fully review literature relating to spas and pilgrimages in future studies. Transformative cultural travel was discussed in 18 articles, including travel related to education, health and wellness, leisure and recreation, ecotourism and sustainable travel, physical activity and conservation. Finally, we analysed 35 articles on volunteering travel including diverse topics like cultural and social aspects of transformative travel, wildlife conservation, ecotourism and sustainable travel, health and wellness, physical activity, education and business.

\subsection{Who are transformative travellers and what are their motivations?}

To provide adequate opportunities for transformative travel, parks need to understand participants' socio-demographic profiles, personal characteristics and travel motivations. For a detailed breakdown of these qualities per travel typology, see Tables 1 and 2, while Figure 2 presents summary profiles of participants according to each typology.

\section{Socio-demographic profiles}

Participants in health and wellness experiences in green spaces were predominantly female travellers, aged 18-59 years (Table 1). Participants were often affluent or mediumlevel income earners, highlighting a positive relationship between affluence and interest in health and wellness (Damijanić \& Šergo, 2013; Hritz, Sidman, \& D'Abundo, 2014; Laesser, 2011). This is unsurprising given current perceptions of wellness as a luxury (Pforr, Hughes, Dawkins, \& Gaunt, 2014) and reflects a broader trend identified in the travel literature wherein older people and subsistence income earners appear less likely to take holidays than younger people and medium-/high-level salary earners (Gilbert \& Abdullah, 2004). Most nbPA studies reported participants of both genders, although studies more commonly noted males, younger (but $>18$ years of age) and midlife age groups (Table 1) within all income groups. Spiritual travel studies reported almost exclusively females, aged 35-60+ years 
(Table 1). Spiritual travellers were commonly described as being affluent- or medium-income earners. Studies of cultural travellers included participants from both genders of all age groups especially younger demographics of 34 years and less, and medium-/low-income earners (Table 1). Of all five typologies, volunteering studies included the broadest group of participants reporting participation by members of both genders, all age (especially younger participants) and income groups (Table 1); that is, nearly equal percentages of papers reported volunteers to be earning either a high, medium or low income. This contrasts with participants in health and wellness travel who were twice as likely to be reported as being affluent compared to earning a low income.

\section{Personal characteristics}

Fourteen personal traits were linked to transformation, most commonly partiality for diverse experiences and "signature strengths" like willingness to learn, open-mindedness, curiosity and adaptability (Table 1), defined as positive character traits triggering actions, desires and feelings that "lead to a recognizable human excellence or instance of human flourishing" (Yearley, 1990, p. 13). In particular, spiritual travellers were characterised by their spiritual inclination and preference for independent travel. This represents mystic travellers, who seek personal enlightenment and spiritual transformation by undertaking activities that encourage reflection, sharing or non-ordinary states of consciousness (e.g. meditation) and secular travellers who intentionally seek healing through therapy for personal growth (Ross, 2010).

[Insert Table 1 here]

\section{Motivations}

Transformative travellers reported 35 multidimensional motivations (Table 2). Travel/escape/adventure and seeking new experiences were common. Nature/scenery, wellbeing, relaxation, stress reduction and health/fitness were the primary distinguishing 
motivations for those participating in health and wellness travel, nbPA and spiritual travel. Volunteer, cultural and nbPA travellers commonly sought enjoyment and excitement. Social networking, experiencing challenges, and personal and skill development were important in nbPA; the latter also predominating in spiritual travel and volunteering (Table 2). NbPA participants mostly sought to achieve wellbeing via action-oriented activities involving risk or challenge (Reisinger, 2013b) or feelings of disorientation from normality (Morgan, 2010b), whereas health and wellness, and spiritual travellers preferred restorative or passive activities. Walking or hiking along park trails were deemed ideal. Cultural and spiritual travellers were more commonly reported to be motivated by sociocultural and authentic experiences than other travellers, which are beneficial for meditative and spiritual quests. Guest-host interaction contributed to authentic volunteering experiences, enabling deep and meaningful social interactions (McIntosh and Zahra (2007).

[Insert Table 2 here]

Personal development and acquiring new skills were significant motivations for nbPA, spiritual and volunteering participants and more common travel motivations for volunteers than professional development, the widely presumed motivation. Apart from personal growth and professional development, Taillon (2007) identified motivations like altruism, travel and adventure, cultural exchange, learning and disseminating personal beliefs; for example, zoo volunteers expressed both altruistic (interpreting wildlife to visitors) and egoistic (learning about wildlife; socialising with like-minded others) motivations (Bixler, Joseph, and Searles (2014).

These multidimensional motivations reflect increasing notions within modern societies of self-improvement as a moral responsibility (Little, 2012; van den Eynde \& Fisher, 2014) and a growing trend away from the traditional sun, sand, escape holidays towards spiritual and physical rejuvenation (Ali-Knight, 2009). Thus, health means healthfulness (van den Eynde 
\& Fisher, 2014), and holidays involve pro-actively regulating and managing oneself, often through conducting nature-based activities (Konu \& Laukkanen, 2010; Little, 2015; van den Eynde \& Fisher, 2014). Similarly, volunteering is deemed to be both a humanitarian act and a vehicle for self- and professional development.

\subsection{Benefits of participating in transformative travel}

Understanding the benefits of transformative travel enables parks to design and convey relevant experiences and outcomes to visitors. Health and wellness, nbPA and spiritual travellers mostly sought benefits purposefully as reported in $77 \%-78 \%$ of the reviewed studies within each travel typology. However, many transformative travellers also achieved incidental benefits, as noted in $40 \%-74 \%$ of the studies depending on the typology, for example from socialising or sightseeing in nature - activities not normally recognised for that.

Reported benefits were short term (44\%-74\%) and long term (44\%-51\%), although explicit details were typically lacking in cultural and volunteering studies. This review associated long-term transformation with regular participation in activities that involved effort and perseverance; increased knowledge, training and skills; offered identity-building outcomes or opportunities for career development; and increased sense of belonging to a special social world (Voigt, Howat, \& Brown, 2010). Activities that take participants beyond their comfort zone combined with the opportunity to reflect and act upon personal insights may stimulate long-term (behavioural) change.

Overall, 28 benefits were achieved regarding participants' health and wellbeing, personal competence, sociocultural relationships, environmental awareness/attitudes, behaviour change and other benefits (Table 3); particularly psychological and emotional wellbeing, social relationship building, environmental appreciation, self-enrichment and physical health (Table 3). 
Primary benefits for health and wellness, nbPA and spiritual travel were psychological and emotional wellbeing, physical health and self-enrichment. Secondary benefits related to building spirituality, environmental awareness or sensitivity, a sense of achievement, regular participation in an activity, improved social relationships and increased independence or confidence. Studies also reported: development of new career or personal skills (nbPA travel), health and lifestyle behavioural change (spiritual travel); and self-enrichment and social and cultural transformations (cultural travel). The findings support that participation generally delivers personal, social and environmental wellbeing benefits (Crust, Keegan, Pigott, \& Swann, 2011; Pretty et al., 2007), and can substitute or supplement counselling and other interventions (Saunders et al., 2014).

[Insert Table 3 here]

Significant opportunities to develop sociocultural relationships were noted in cultural travel and volunteering (Table 3). Volunteers also attained economic benefits via networking and professional development. Common volunteering benefits were social, cultural, psychological and emotional well-being. Moderately frequently reported benefits included increased sense of independence, new career and personal skills, self-enrichment, a sense of achievement and appreciation for the environment. Lack of prolonged experience was linked to a lack in personal benefits from volunteering (Zavitz \& Butz, 2011).

Nearly half of all health and wellness studies recorded behavioural change - most commonly, improved management of health and lifestyle, or increased sense of personal responsibility. Long-term behaviour changes were deemed necessary to deliver on sustainability and global wellness goals. Participants of thematic guided tours in Australian national parks reported a number of behaviour change benefits including building strong personal relationships; committing to regular exercise; increasing environmental values and stewardship; developing new knowledge and skills; and making physical activity a habit 
(Wolf et al., 2015). Conversely, behavioural change was rarely reported in volunteering, and Coghlan and Weiler (2015) concluded that transformation, even if it is strong at an internal level, may not result in behaviour change that the individual tourist is aware of or could be quantified by a researcher. However, transformation in attitudes and values, more commonly noted, was considered conducive to measurable behaviour change. Other occasionally reported types of behavioural change revolved around social relationship building, living sustainably, environmentally conscious purchasing behaviour, donating time/money towards good causes and taking political action.

\subsection{What makes travel experiences transformative?}

Identifying experience characteristics that drive transformation is critical for designing outcome-focused park visitor experiences. Considerably more studies on nbPA (70\%), spiritual (56\%), and health and wellness (55\%) travel, explored the experience-benefit relationship compared to cultural travel (30\%) and volunteering (23\%). Presumably, investigating relationships between experience characteristics and outcomes is comparatively straightforward regarding physical activities where tangible outputs (e.g. energy expenditure) are quantifiable (den Breejen, 2007; Saunders et al., 2014; Wolf \& Wohlfart, 2014).

Twenty-three experience characteristics drove transformation, particularly various types of immersion in the experience (91\%, cumulative across all travel typologies), reconnection (cumulative 67\%), and opportunity to escape (cumulative 54\%) (Table 4). Often articles described general immersion; however, specific types of immersion were also discerned for achieving transformation, for example immersion in social and active situations was important in nbPA and volunteering. Participatory and interactive immersion drove transformation particularly when volunteering. Cultural immersion featured highly in cultural experiences and volunteering. Immersive activities enabling escape from people's daily routines can facilitate physical and mental restoration (Kaplan \& Kaplan, 1989; Lehto, 2013). 
The studies indicated that mental, emotional, physical and environmental challenges often go together and are commonly associated with immersive and participatory activities. Studies frequently described mastering of challenges as a vehicle for immersion.

[Insert Table 4 here]

Nature-based physical or cultural activities provide opportunities to disengage from everyday events and to reconnect with a more authentic natural past (Little, 2012).

Opportunities for reconnection with oneself (health and wellness, nbPA, spiritual travel), with land and heritage (nbPA), and sometimes with one's family through social immersion (nbPA, volunteering and cultural experiences) transformed participants (Table 4). Parks were described as social places where people spend time with family, friends and other groups (Weber \& Anderson, 2010). Ramkissoon, Smith and Weiler (2013) discuss the strength of links between place social bonding and pro-environmental behaviour in their in-depth study of an Australian National Park. And the presence of a like-minded community can encourage individuals on a journey of reconnection with others (Moscardo, 2011; Smith \& Kelly, 2006a). Parks therefore maintain healthy communities through their role as social places and through the formation of social capital (Barton et al., 2009).

Regular participation was critical for achieving transformation through nbPA or spiritual activity, and in health and wellness travel and volunteering but less so (Table 4). Transformative travellers tend to be experienced, assertive and likely to repeat participation in the future (Konu \& Laukkanen, 2010). Thematically connected park tours (e.g. longdistance hikes consisting of individual episodes) motivated participants to complete the whole series (Wolf et al. (2015). Prolonged participation was significant in driving the lifechanging power of travel (Nash, 1996). Sustaining benefits long term can be a strong incentive for regular participation (Kelly \& Smith, 2009; Little, 2012, 2015) and may result 
in attachment to certain places encouraging revisitation (Graefe et al., 2000; Sharpley \& Jepson, 2015).

Acculturation uniquely triggered transformation in voluntourists (15\%) but should be relevant also for cultural travel. Regarding the international voluntourism experience and its impact on individuals upon returning home, acculturation concerns the notion of change from one mental state to another following intercultural interaction, fuelled by geographical mobility (Grabowski \& Reisinger, 2013). Here, voluntourism fostered personal growth and other transformations upon re-entry, due to interactions with the host community and postexperience reflection.

\section{Conclusions and implications for transformative market niche and experience development in parks}

This study provides a rare contribution to linking specific experiential traits to participant outcomes while describing transformative traveller characteristics and motivations. To demonstrate how these findings can be applied practically to sustainable experience development, marketing and monitoring in parks we have developed two conceptual models. The "transformative travel framework" (Figure 1) depicts the inter-relationships between participant and experience characteristics that trigger a transformation process (Mezirow, 1991), and the experience benefits to be attained by participants, as well as outcomes for parks. The "model of transformative travel market niches for protected areas" (Figure 2) summarises the key quantitative results for participant profiles within each of the five transformative travel typologies and their associated experience-outcome relationships. We explain the practical application of these models below.

\subsection{Transformative travel framework}

The transformative travel framework shows the interrelationships between transformation triggers, including participant characteristics and motivations, and experience characteristics, 
resulting in positive outcomes for participants, and for experience providers. This framework can be used to guide future validation studies since limited empirical evidence exists (Moore, Rodger, \& Taplin, 2015). A notable exception is Nowacki's (2009) study on the relationship between performance of the attraction, satisfaction, benefits and behavioural intentions of zoo and museum visitors. Critically, visitors revisited or recommended attractions based on their assessment of long-term benefits accrued, rather than momentary satisfaction, underpinning the importance of assessing the diverse benefits of visiting parks as a predictor of destination loyalty, rather than relying on conventional assessments of visitor satisfaction. Nowacki's study highlights how performance tends to be judged on the physical attributes of attractions, such as sources of information, or level of service. In contrast, our framework focuses on underlying experience design features that are fundamental to the transformative process, such as immersion or challenge.

Also included in the framework are transformative characteristics of the environment in which travel takes place. Parks can provide various experiences within diverse environments (e.g. Graefe et al., 2000; Lane \& Kastenholz, 2015; Williams \& Harvey, 2001), offering transcendence in sublime landscapes (Smith \& Kelly, 2006a). National parks in particular offer access to awe-inspiring or challenging places and activities that significantly contrast with people's ordinary lives (Pearce et al., 2017; Wolf et al., 2015); ideal conditions for triggering the transformation process (Mezirow, 1991). We present environmental experience traits that the literature links to transformation (Figure 1), although our review focused on broad types of settings where transformative travel reportedly occurred, such as natural, rural, foreign or urban environments.

The framework (Figure 1) conceptualises how transformative travel can benefit parks by achieving participant satisfaction and destination loyalty captured through increased visitor numbers linked to word-of-mouth recommendation and repeat visitation (Sharpley \& Jepson, 
2015; Wolf et al., 2015). This is exemplified by previous positive experience with well-being holidays (Konu, 2010) and activities that contribute to longer term health or lifestyle changes (Ali-Knight, 2009; Little, 2012) . Regular or repeat visits encouraged place attachment (López-Mosquera \& Sánchez, 2013). Benefits arising from transformative travel may foster more nurturing individuals (Dickson, Gray, \& Mann, 2008; Wolf et al., 2015) and flow-on effects of personal change to social and cultural groups wanting to give back to nature and the community can benefit parks. Volunteers at a zoo developed numerous conservation behaviours which, linked with the volunteer program's immersive participatory methods, led to participant transformations that encouraged ongoing involvement (Bixler et al., 2014). Desire to share one's transformative volunteer park experience can help park management through word-of-mouth (Boz \& Palaz, 2007), encouraging others to participate in volunteer park experiences (Sin, 2009), and marketing and research (Grimm \& Needham, 2012). Thus, parks providing transformative travel experiences can fulfil their dual mandate of conserving natural areas and providing visitor experiences, while contributing to park sustainability.

[Insert Figure 1 here]

\subsection{Developing transformative travel market niches for protected areas}

Park managers ought to design and deliver various transformative experiences based on the personal profiles, motivations and benefits sought by different kinds of transformative travellers as identified in this review and summarised in our model of transformative travel market niches for protected areas (Figure 2). The findings of this review can inform transformative experience development as a range of market niches for protected areas as the following examples demonstrate.

[Insert Figure 2 here]

Park managers could develop diverse walking experiences to nurture visitors' desire to protect natural and cultural areas (López-Mosquera \& Sánchez, 2013; Pretty et al., 2007; 
Wolf et al., 2015). Walking activities can satisfy the multidimensional motivations held by members of different transformative travel typologies (Figure 2). Transformative walking experiences should integrate the experience characteristics identified in this review (Section 3.5), with the aim of challenging people and providing opportunity for immersion, reconnection, escape and regular participation (Figure 2). The importance of these experience characteristics was consistent across travel typologies; however, the model's sensitivity allows for consideration of individual frequencies in the experience design.

Park managers may offer experiences that align closely with one travel typology or are more holistic and cover a spectrum of typologies. For example, a walking experience developed for the nbPA market niche would emphasise primarily physical activity and should involve various forms of challenge (physical, mental, etc.) coupled with opportunity for social immersion (nbPA typology, Figure 2). More holistic walking experiences could extend their focus from nbPA to cultural realms (food gathering, introduction of medicinal plants, offering local products, ingredients or treatments); spirituality (contemplation); general health and well-being (physical, sensory, social, cognitive restoration); or volunteering (clean ups), each emphasising the unique benefits summarised in our conceptual model. To provide memorable emotional journeys, participants’ expectations, skills and experience levels must be matched with adequately challenging activities (Pomfret, 2012). These are less important if a spiritual context is added to the walk, as described below. Regular participation is important for both nbPA and spiritual travellers but less so if the experience is more generally targeted towards health and wellness, or cultural travel.

Special-interest walks may be packaged as holistic experiences catering to the various physical, economic, learning and social requirements of different visitors and broadening their market appeal. Barefoot and meditative walks, for example, could be positioned as experiences that deliver benefits commonly noted for psychological, physical, emotional and 
spiritual health and wellbeing, and self-enrichment. In barefoot walks people typically store their shoes at the beginning of a path and walk barefoot on different natural materials or balancing stations. This encourages the feel of different textures and terrain types, relaxing the senses, assisting with a healthier posture, strengthening muscles and facilitating mental relaxation. Meditative walks consist of different stations with thought-provoking interpretive content, possibly with a religious meaning, relevant to its natural context. This could include sculptures or stone assemblies to be followed in deep reflection. A cultural variation conveys Indigenous interpretations of the land through relevant meditative stations. Similarly, in poetry walks different poems are presented along a walking path to entertain and stimulate thought processes. Silent walks are another variation, honouring peace, quiet and solitude, leaving ample space for introspective thought. Offering these alternatives to traditional (non)interpretive walks close to visitor centres would benefit many by conveying the reflective purpose of parks and enabling deep engagement with nature in a playful manner. In urban settings, such experiences contrast with other recreational offers and make a memorable point of difference with significant marketing potential. There is also great potential for children's barefoot park walks in natural play areas. Vita/fitness parcours along a course that includes various exercises can also attract transformative travellers to parks. These experiences actively and socially immerse visitors and draw on mental, emotional and physical challenges often related to self-development and reconciliation of body, mind and spirit (Smith \& Kelly, 2006a).

Long-distance hikes and guided walking groups play a special role in long-term and behavioural transformation because they challenge participants and require a regular commitment. Situated at one end of the social spectrum are highly challenging activities which encourage people to test their own resolve and help them achieve some degree of personal development (e.g. adventure recreation activities) and independence. At the other 
end, less challenging, family-oriented activities could focus on enjoyment, socialising and cultural learning (e.g. outdoor recreation activities). Providing different trail grades and lengths, incorporating appropriate signage and offering opportunities to experience cultural heritage sites, stimulating landscapes, flora and fauna, interesting geological features and visitor precincts can facilitate reconnection with land and heritage.

Our model of transformative travel market niches for protected areas indicates that the holistic walking experience could include additional components to upscale or downscale offerings depending on the target audience and participants’ willingness to pay for different kinds of experiences. Cultural travellers and volunteers were particularly willing to pay for their experiences, indicating a demand for commercial or even luxury experiences. However, to make transformative travel freely accessible, parks should offer alternatives so visitors can achieve free or low-cost park benefits (Hansmann, Hug, \& Seeland, 2007). Creating active participation-focused programmes whereby park visitors are key to shaping their experiences is instrumental. Cultural walks should use creative approaches where visitors personalise their experience, actively learn and develop skills, rather than a guide interpreting the surrounding culture for them (Richards \& Wilson, 2006). Gastronomy was highlighted as driving transformation (21\% of publications); parks could promote healthy-lifestyle choices by providing visitors with access to locally grown, culturally authentic and healthy food at park-based food outlets or during the above-described experiences. The United States National Park Service, for example, manages such a "Healthy and Sustainable Food Program". Visitor education should be a compulsory element of transformative travel, drawn from an international regulatory framework influencing activities in protected areas, to achieve sustainability. Education is particularly important about the value of incidental, nondeliberate transformative activities as highlighted below. The experience becomes sustainable if participants appreciate and communicate its value, are regularly attracted to and develop or 
maintain a sense of support for parks, but cause little environmental impact while there (Wolf \& Croft, 2010; Wolf \& Croft, 2012). Managers must inspire enduring changes of behaviour that last beyond the experience (Lean, 2009).

It is also worth noting that park managers may implement transformative travel ideas directly or through working with NGOs, social enterprises or by partnering with private sector business. Getzner, Lange Vik, Brendehaug and Lane (2014) provide a good example of private-public sector protected area partnerships: there are many others.

\subsection{Experience marketing}

Finely-tuned marketing, communication and interpretation strategies are necessary to appeal to transformative travellers and promote the specific experiences they seek. Park managers need to convey relevant information especially about experiential benefits. For example appealing to nbPA participants typically motivated by health and wellbeing, personal development and enjoyment/excitement, Wolf and Wohlfart (2014) suggested connecting trip/trail characteristics with associated effort and resulting positive outcomes; and communicating the suitability of tracks on park social media for different purposes to ensure the experience delivered matches skills and expectations.

Social interactions form an integral and enjoyable part of transformative walking experiences, therefore marketing could highlight related psychological and physical wellbeing; social benefits include shared experiences, camaraderie and a sense of community; and improved self-competence including building confidence, coping strategies and a sense of purpose. However, marketing strategies should highlight aspects of walking that appeal to solo and group visitors as participants in health and wellbeing, nbPA and spiritual travel activities were divided into these two groups: For independent walkers, marketing should emphasise independent access to natural places for activity and contemplation, offering peace, solitude and self-organised wellness experiences in undeveloped natural environments. 
For the social walker, marketing should emphasise opportunities to spend time with family, friends and others and promote post-experience sharing in social media and newsletters.

Better communication of potential benefits of incidentally transformative activities such as sightseeing or socialising enables people to attribute greater importance to the critical services that public green spaces offer (Barton et al., 2009; Hansmann et al., 2007; Pretty et al., 2007; Wolf \& Wohlfart, 2014).

Marketing should aim to appeal to the typical characteristics of the transformative traveller like intellectual curiosity, an emotional need or desire for challenge, and a mindset required to resolve the dilemma intrinsic to the transformation process (Kottler, 1998). Participants possessing such signature strengths benefit from travel activities that activate them in new and different ways (Coghlan, 2015). Our findings concord with Kottler (1998) and suggest that participants approach transformation with a pro-active attitude. NbPA participants were the most adventurous and curious of all transformative travellers, commonly seeking diverse and extraordinary experiences that stretch and challenge them. These signature strengths existed among participants in long-distance walking, adventure tourism (e.g. hiking, mountaineering and white-water rafting) and outdoor education, suggesting that parks could benefit from developing such transformative travel experiences.

\subsection{Future research and monitoring}

This review revealed important avenues for future research. Although our conceptual model (Figure 2) presents the most commonly reported transformative traveller characteristics, this review also highlighted that several groups are less commonly reported to participate, including the young and elderly, people with special conditions, and the less affluent (Crust et al., 2011; Davidson, 2001; den Breejen, 2007; Hansmann et al., 2007; McLeod \& Allen-Craig, 2007; Pomfret, 2012; Wolf et al., 2015; Wolf \& Wohlfart, 2014). Seniors are typically under-represented in parks often due to safety concerns (Scott \& 
Jackson, 1996). However, studies indicated that those over 60 years and retirees engage in diverse activities and are highly appreciative of personal benefits gained from long-distance walking and thematic guided tours (den Breejen, 2007; Wolf et al., 2015) suggesting this market could be better developed in parks. Guided walking tours in particular provide a safe and informative option for this group.

Current understanding of experiential qualities that drive transformation is insufficient, as is measurement of the type and duration of benefits received, especially beyond the life of an activity or program. Benefits were discussed or alluded to but not always measured and research into the different transformative travel typologies was significantly imbalanced; this was particularly true for studies on spiritual and cultural travel, indicating the need for effective research and monitoring and implementation of longitudinal research to capture the spectrum of long-term benefits linked to specific experience traits. A limitation of our quantitative literature review approach is that more intensely researched travel typologies appear to be linked to more experience characteristics and benefits, an issue to be addressed as new research increases our understanding of transformative spiritual and cultural travel. Monitoring will provide park agencies with evidence regarding the efficacy of specific experiences in delivering benefits to participants and to the agency; this evidence can be communicated to key stakeholders since the attainment of benefits was linked to key performance measures including visitor satisfaction, destination loyalty and word-of-mouth recommendation (Damijanić \& Šergo, 2013; Hritz et al., 2014; Lehto, 2013; Wolf et al., 2015). Comparative studies are needed to establish the market position of proprietary park activities against competing products. Our transformative travel framework (Figure 1), market niche model (Figure 2), and tables provide in-depth lists of experience traits and benefits to guide monitoring efforts and variables to be measured in comparative studies, and a basis for future validation studies. 
Transformative travel has the potential to encourage short- and long-term behaviour change. Yet surprisingly, behaviour change was rarely reported in most studies on cultural and volunteering travel, activities associated with the traits and benefits typically thought to engender long-term transformation. Further research is required to inform volunteering organisations about how to maximise the experiential benefits of transformative tourism to participants.

Finally, the nbPA studies reviewed included participants already engaged in nbPA, rather than the habitually inactive, who are typically harder to reach. Therefore, a major challenge is to reach sedentary and socially excluded individuals (Pretty et al., 2007). Importantly, future research could identify and characterise currently disengaged sectors of society, whose members may benefit from participating in transformative travel conducted in protected areas.

\section{References}

Ali-Knight, J. (2009). Case study 1. Yoga tourism. In R. Bushell \& P. J. Sheldon (Eds.), Wellness and Tourism: Mind, Body, Spirit, Place (pp. 84-95). New York, USA: Cognizant Communication Corporation.

Barton, J., Hine, R., \& Pretty, J. (2009). The health benefits of walking in greenspaces of high natural and heritage value. Journal of Integrative Environmental Sciences, 6(4), 261278. doi: $10.1080 / 19438150903378425$

Bixler, R. D., Joseph, S. L., \& Searles, V. M. (2014). Volunteers as Products of a Zoo Conservation Education Program. The Journal of Environmental Education, 45(1), 5773.

Boz, I., \& Palaz, S. (2007). Factors influencing the motivation of Turkey's community volunteers. Nonprofit and Voluntary Sector Quarterly, 36(4), 643-661.

Brightsmith, D. J., Stronza, A., \& Holle, K. (2008). Ecotourism, conservation biology, and volunteer tourism: A mutually beneficial triumvirate. Biological Conservation, 141(11), 2832-2842.

Buckley, R. (2009). Parks and tourism PLoS Biology, 7(6), 1-6.

Bushell, R., \& Sheldon, P. J. (2009a). Wellness and tourism: body, mind, spirit and place. New York: Cognizant Communication Corporation.

Bushell, R., \& Sheldon, P. J. (2009b). Wellness and tourism: Mind, body, spirit, place. New York, USA: Cognizant Communication.

Caissie, L. T., \& Halpenny, E. A. (2003). Volunteering for nature: motivations for participating in a biodiversity conservation volunteer program. World Leisure Journal, 45(2), 3850. 
Christie, M. F., \& Mason, P. A. (2003). Transformative tour guiding: Training tour guides to be critically reflective practitioners. Journal of Ecotourism, 2(1), 1-16.

Coghlan, A. (2015). Tourism and health: using positive psychology principles to maximise participants' wellbeing outcomes-a design concept for charity challenge tourism. Journal of Sustainable Tourism, 23(3), 382-400.

Coghlan, A., \& Weiler, B. (2015). Examining transformative processes in volunteer tourism. Current Issues in Tourism, 1-16.

Crust, L., Keegan, R., Pigott, D., \& Swann, C. (2011). Walking the walk: a phenomenological study of long distance walking. Journal of Applied Sport Psychology, 23(3), 243-262.

Daengbuppha, J., Hemmington, N., \& Wilkes, K. (2006). Using grounded theory to model visitor experiences at heritage sites: Methodological and practical issues. Qualitative Market Research: An International Journal, 9(4), 367-388.

Damijanić, A. T., \& Šergo, Z. (2013). Determining travel motivations of wellness tourism. Economic Thought and Practice, June(1), 3-20.

Davidson, L. (2001). Qualitative research and making meaning of adventure: a case study of boys' experiences of outdoor education at school. Journal of Adventure Education and Outdoor Learning, 1(2), 11-20.

den Breejen, L. (2007). The experiences of long distance walking: A case study of the West Highland Way in Scotland. Tourism Management, 28, 1417-1427.

Dickson, T., Gray, T., \& Mann, K. (2008). Australian Outdoor Adventure Activity Benefits Catalogue. Canberra: Centre for Tourism Research, University of Canberra.

Driver, B. L. (2008a). What is outcomes-focused management? In B. L. Driver (Ed.), Managing to Optimize the Beneficial Outcomes of Recreation (pp. 19-37). State College, PA: Venture Publishing, Inc..

Driver, B. L. (2008b). Why outcome-focused management is needed. In B. L. Driver (Ed.), Managing to Optimize the Beneficial Outcomes of Recreation (pp. 1-17). State College, PA: Venture Publishing, Inc.

Dwyer, L., Edwards, D., Mistilis, N., Roman, C., Scott, N., \& Cooper, C. (2008). Megatrends underpinning tourism to: Analysis of Key Drivers for Change. Gold Coast, Australia: Cooperative Research Centre for Sustainable Tourism Pty Ltd.

Eagles, P. F. J. (2014). Research priorities in park tourism. Journal of Sustainable Tourism, 22(4), 528-549.

Eagles, P. F. J., \& McCool, S. F. (2002). Tourism in National Parks and Protected Areas. Wallingford: $C A B$ International.

Filep, S., \& Pearce, P. (2013). Tourist Experience and Fulfilment: Insights from Positive Psychology (Vol. 31). London: Routledge.

Gelter, H. (2010). Total experience management: a conceptual model for transformational experiences within tourism: pp. 46-78 in Conference proceedings. The Nordic Conference on Experience 2008. Research, Education and Practice in Media pp. 4678. Medusa Group of Vaasa Consortium of Higher Education, Vaasa, Finland. Tritonia 2010. $195 \mathrm{p}$.

Getzner, M., Vik, M. L., Brendehaug, E., \& Lane, B. (2014). Governance and management strategies in national parks: Implications for sustainable regional development. International Journal of Sustainable Society, 6(1-2), 82-101.

Gilbert, D., \& Abdullah, J. (2004). Holidaytaking and the sense of well-being. Annals of Tourism Research, 31(1), 103-121. 
Grabowski, S., \& Reisinger, Y. (2013). Acculturation, re-entry and transformation: the story of a volunteer tourist. In Y. Reisinger (Ed.), Transformational Tourism: Tourist Perspectives (pp. 183-198). Oxfordshire, UK: CABI.

Graefe, A. R., Thapa, B., Confer, J. J., \& Absher, J. D. (2000). Relationships between trip motivations and selected variables among Allegheny National Forest visitors. USDA Forest Service Proceedings RMRS-P-15, 4, 107-112.

Grimm, K. E., \& Needham, M. D. (2012). Internet promotional material and conservation volunteer tourist motivations: A case study of selecting organizations and projects. Tourism Management Perspectives, 1, 17-27.

Hajkowicz, S., Cook, H., \& Boughen, N. (2013). The Future of Tourism in Queensland: Global Mega Trends Creating Opportunities and Challenges Over the Coming Twenty Years. Canberra, Australia: CSIRO.

Hansmann, R., Hug, S.-M., \& Seeland, K. (2007). Restoration and stress relief through physical activities in forests and parks. Urban Forestry \& Urban Greening, 6(4), 213225.

Hewlett, D., \& Edwards, J. (2013). Beyond Prescription: Community Engagement in the Planning and Management of National Parks as Tourist Destinations. Tourism Planning \& Development, 10(1), 45-63.

Higham, J., Cohen, S. A., Peeters, P., \& Gössling, S. (2013). Psychological and behavioural approaches to understanding and governing sustainable mobility. Journal of Sustainable Tourism, 21(7), 949-967.

Hritz, N. M., Sidman, C. L., \& D'Abundo, M. (2014). Segmenting the college educated Generation $Y$ health and wellness traveler. Journal of Travel \& Tourism Marketing, 31(1), 132-145. doi: 10.1080/10548408.2014.861727

Kaplan, R., \& Kaplan, S. (1989). The experience of nature: A psychological perspective. Cambridge: Cambridge University Press.

Kelly, C., \& Smith, M. (2009). Holistic tourism: integrating body, mind spirit. In R. Bushell \& P. J. Sheldon (Eds.), Wellness and Tourism: Mind, Body, Spirit, Place (pp. 69-83). New York, NY: Cognizant Communication Corporation.

Konu, H. (2010). Identifying potential wellbeing tourism segments in Finland. Tourism Review, 65(2), 41-51.

Konu, H., \& Laukkanen, T. (2010). Predictors of Tourists' Wellbeing Holiday Intentions in Finland. Journal of Hospitality and Tourism Management, 17(1), 144-149.

Kottler, J. A. (1997). Travel that can change your life: How to create a transformative experience. San Francisco, CA: Jossey-Bass.

Kottler, J. A. (1998). Transformative travel. The Futurist, 32(3), 24-29.

Kottler, J. A. (2002). Transformative travel: International counseling in action. International Journal for the Advancement of Counseling, 24, 207-210.

Kottler, J. A., \& Montgomery, M. (2000). Prescriptive travel and adventure-based activities as an adjunct to counseling. Guidance and Counseling, 15(2), 8-11.

Krippendorf, J. (1988). Der neue Tourist.... Eine Charakterisierung [The new tourist: key charcteristics] In J. Krippendorf, P. Zimmer \& H. Glauber (Eds.), Für einen anderen Tourismus. Probleme, Perspektiven, Ratschläge [Towards an Alternative Tourism: problems - persepctives - advice.] (pp. 66-68). Frankfurt am Main: Fischer Taschenbuch Verlag.

Laesser, C. (2011). Health travel motivation and activities: insights from a mature marketSwitzerland. Tourism Review, 66(1/2), 83-89. 
Lane, B., \& Kastenholz, E. (2015). Rural tourism: the evolution of practice and research approaches - towards a new generation concept? Journal of Sustainable Tourism, 23, 1133-1156. doi: 10.1080/09669582.2015.1083997

Lean, G. L. (2005). Transformative travel and the creation of sustainability ambassadors: Literature review. Sydney: Unpublished Bachelors project, University of Western Sydney.

Lean, G. L. (2009). Transformative travel: inspiring sustainability. In R. Bushell \& P. J. Sheldon (Eds.), Wellness and tourism: Mind, body, spirit, place (pp. 191-205). New York, NY: Cognizant Communication Corporation.

Leed, E. J. (1991). The mind of the traveler: From Gilgamesh to global tourism. New York, NY: Basic Books.

Lehto, X. Y. (2013). Assessing the perceived restorative qualities of vacation destinations. Journal of Travel Research, 52(3), 325-339. doi: 10.1177/0047287512461567

Leslie, D. (1986). Tourism and conservation in national parks. Tourism Management, 7(1), 52-56.

Little, J. (2012). Transformational tourism, nature and wellbeing: new perspectives on fitness and the body. Sociologia Ruralis, 52(3), 257-271. doi: 10.1111/j.14679523.2012.00566.x

Little, J. (2015). Nature, wellbeing and the transformational self. The Geographical Journal, 181(2), 121-128.

López-Mosquera, N., \& Sánchez, M. (2013). Direct and indirect effects of received benefits and place attachment in willingness to pay and loyalty in suburban natural areas. Journal of Environmental Psychology, 34(0), 27-35.

Manning, R. E. (1999). Studies in outdoor recreation: Search and research for satisfaction. Corvallis, OR: Oregon State University Press.

McIntosh, A. J., \& Zahra, A. (2007). A cultural encounter through volunteer tourism: Towards the ideals of sustainable tourism? Journal of Sustainable Tourism, 15(5), 541-556.

McLeod, B., \& Allen-Craig, S. (2007). What outcomes are we trying to achieve in our outdoor education programs? Australian Journal of Outdoor Education, 11, 41-49.

Merriam, S. B., \& Caffarella, R. (1999). Learning in adulthood 2nd ed: San Francisco, CA: Jossey-Bass.

Mezirow, J. (1991). Transformative Dimensions of Adult Learning. San Francisco, CA: JosseyBass.

Mezirow, J. (2012). Learning to think like an adult: Core concepts of transformational learning theory. In E. Taylor, P. Cranton \& Associates (Eds.), The handbook of transformative learning: Theory, research, and practice. (pp. 73-95). San Francisco: John Wiley and Sons.

Moore, S. A., Rodger, K., \& Taplin, R. (2015). Moving beyond visitor satisfaction to loyalty in nature-based tourism: a review and research agenda. Current Issues in Tourism, 18(7), 1-17.

Morgan, A. D. (2010a). Journeys into transformation: Travel to an "Other" place as a vehicle for transformative learning. Journal of Transformative Education, 8(4), 246-268.

Morgan, M., \& Watson, P. (2009). Unlocking the Shared Experience. In M. Kozak \& A. DeCrop (Eds.), Handbook of Tourist Behavior: Theory \& Practice (pp. 116-132). New York: Taylor \& Francis.

Morgan, P. (2010b). Towards a developmental theory of place attachment. Journal of Environmental Psychology, 30, 11-22. 
Moscardo, G. (2011). Searching for well-being: exploring change in tourist motivation. Tourism Recreation Research, 36(1), 15-26.

Moyle, B. D., Weiler, B., \& Moore, S. A. (2014). Benefits that matter to managers: an exploratory study of three national park management agencies. Managing Leisure, 19(6), 400-419.

Nash, D. ( 1996). Anthropology of tourism: Pergamon, Oxford, NY.

Nowacki, M. M. (2009). Quality of visitor attractions, satisfaction, benefits and behavioural intentions of visitors: Verification of a model. International Journal of Tourism Research, 11(3), 297-309.

Pearce, J., Strickland-Munro, J., \& Moore, S. A. (2017). What fosters awe-inspiring experiences in nature-based tourism destinations? Journal of Sustainable Tourism, 25(3), 362-378.

Pergams, O. R. W., \& Zaradic, P. A. (2008). Evidence for a fundamental and pervasive shift away from nature-based recreation. PNAS, 105(7), 2295-2300.

Pforr, C., Hughes, M., Dawkins, M., \& Gaunt, E. (2014). Nature-based wellness tourism. The case of the Margaret River region in Western Australia. In C. Voigt \& C. Pforr (Eds.), Wellness Tourism: A Destination Perspective (pp. 176-187). Oxford: Routledge.

Pickering, C., \& Byrne, J. (2014). The benefits of publishing systematic quantitative literature reviews for PhD candidates and other early-career researchers. Higher Education Research \& Development, 33(3), 534-548.

Pine, B. J., \& Gilmore, J. H. (1999). The Experience Economy: Work Is Theatre and Every Business a Stage. Boston, MA: Harvard Business School Press.

Pomfret, G. (2012). Personal emotional journeys associated with adventure activities on packaged mountaineering holidays. Tourism Management Perspectives, 4(145-154), 145.

Pretty, J., Peacock, J., Hine, R., Sellens, M., South, N., \& Griffin, M. (2007). Green exercise in the UK countryside: Effects on health and psychological well-being, and implications for policy and planning. Journal of Environmental Planning and Management, 50(2), 211-231.

Ramkissoon, H., Smith, L. D. G., \& Weiler, B. (2013). Relationships between place attachment, place satisfaction and pro-environmental behaviour in an Australian national park. Journal of Sustainable Tourism, 21(3), 434-457.

Raymond, E. M., \& Hall, C. M. (2008). The development of cross-cultural (mis) understanding through volunteer tourism. Journal of Sustainable Tourism, 16(5), 530-543.

Reisinger, Y. (2013a). Connection between travel, tourism and transformation. In Y. Reisinger (Ed.), Transformational Tourism: Tourist Perspectives (pp. 27-32). Wallingford, Oxon: CABI.

Reisinger, Y. (2013b). Transformation and transformational learning theory. In Y. Reisinger (Ed.), Transformational Tourism: Tourist Perspectives (pp. 17-26). Oxfordshire, UK: CABI.

Reisinger, Y. (Ed.). (2013c). Transformational Tourism: Tourist Perspectives. Wallingford, Oxon: CABI.

Richards, G., \& Wilson, J. (2006). Developing creativity in tourist experiences: A solution to the serial reproduction of culture? Tourism Management, 27(6), 1209-1223.

Roberson, D. N. (2002). Modern day explorers-the way to a wider world World Leisure, $3(35-42)$. 
Ross, S. L. (2010). Transformative Travel: An Enjoyable Way to Foster Radical Change. ReVision, 32(1), 54-61.

Saunders, R. E., Laing, J. H., \& Weiler, B. (2014). Personal transformation through longdistance walking. In S. Felip \& P. L. Pearce (Eds.), Tourist Experience and Fulfilment: Insights from Positive Psychology. (pp. 127-146). Oxford: Routledge.

Schwartz, Z., \& Lin, L.-C. (2006). The impact of fees on visitation of national parks. Tourism Management, 27(6), 1386-1396.

Scott, D., \& Jackson, E. L. (1996). Factors that limit and strategies that might encourage people's use of public parks. Journal of Park and Recreation Administration, 14(1), 117.

Sharpley, R. A. J., \& Jepson, D. (2015). More than sense of place? Exploring the emotional dimension of rural tourism experiences. Journal of Sustainable Tourism, 23(8\&9), 1157-1178.

Sin, H. L. (2009). Volunteer tourism - "involve me and I will learn"? Annals of Tourism Research, 36(3), 480-501.

Smith, M., \& Kelly, C. (2006a). Holistic tourism: Journeys of the self? Tourism Recreation Research, 31(1), 15-24.

Smith, M., \& Kelly, C. (2006b). Wellness tourism. Tourism Recreation Research, 31(1), 1-4.

Smith, M., \& Puczkó, L. (2014). Health, Tourism and Hospitality. Wellness, Spas and Medical Travel. Abingdon, Oxon: Routeledge.

Stoddart, H., \& Rogerson, C. M. (2004). Volunteer tourism: The case of habitat for humanity in South Africa. Geo Journal, 60, 311-318.

Sugiyama, T., Leslie, E., Giles-Corti, B., \& Owen, N. (2008). Associations of neighborhood greenness with physical and mental health: do walking, social coherence and local social integration explain the relationships? Journal of Epidemiology and Community Health, 62(5), 1-6.

Sundbo, J., \& Darmer, P. (2008). Creating experiences in the experience economy. Cheltenham, UK: Edward Elgar Publishing.

Taillon, J. (2007). The identification of motivation in voluntourists: Particularly extrinsic motivators in vacation-minded volunteer tourism participants. (MBA Thesis), University of Guelph, Guelph, Canada.

Torland, M., Weiler, B., Moyle, B. D., \& Wolf, I. D. (2015). Are your ducks in a row? External and internal stakeholder perceptions of the benefits of parks in New South Wales, Australia. Managing Sport and Leisure, 20(4), 211-237.

Tucker, T., Allen, L., \& Driver, B. (2008). Implementing OFM in municipal parks and recreation departments. In B. L. Driver (Ed.), Managing to Optimize the Beneficial Outcomes of Recreation (pp. 75-94). State College, PA: Venture Publishing, Inc.

Uysal, M., Sirgy, M. J., Woo, E., \& Kim, H. (2016). Quality of life (QOL) and well-being research in tourism. Tourism Management, 53, 244-261.

van Aalst, J. (2010). Using Google Scholar to estimate the impact of journal articles in education. Educational Researcher, 39(5), 387-400.

van den Eynde, A., \& Fisher, A. (2014). The social construction of travelling for well-being in Australia. In M. Smith \& L. Puczkó (Eds.), Health, Tourism and Hospitality: Wellness, Spas and Medical Travel (2nd ed., pp. 391-396). Abingdon, Oxon: Routledge.

Voigt, C., Brown, G., \& Howat, G. (2011). In Search For Transformation: An Examination of the Benefits Sought by Wellness Tourists. Tourism Review, 66(1\&2), 16-30. 
Voigt, C., Howat, G., \& Brown, G. (2010). Hedonic and eudaimonic experiences among wellness tourists: An exploratory enquiry. Annals of Leisure Research, 13(3), 541-562.

Voigt, C., \& Pforr, C. (2013). Wellness Tourism: A Destination Perspective (Vol. 33). Abingdon, Oxon: Routledge.

Wearing, S. (2001). Volunteer Tourism: Experiences That Make a Difference. Wallingford, Oxon: $C A B$ International.

Weber, D., \& Anderson, D. (2010). Contact with nature: Recreation experience preferences in Australian parks. Annals of Leisure Research, 13, 46-69.

Weiler, B., Moore, S. A., \& Moyle, B. (2013). Building and sustaining support for national parks in the 21st century: why and how to save the national park experience from extinction. Journal of Park and Recreation Administration, 31, 110-126.

Whitelaw, P. A., King, B. E., \& Tolkach, D. (2014). Protected areas, conservation and tourism-financing the sustainable dream. Journal of Sustainable Tourism, 22(4), 584603.

Williams, A. (2006). Tourism and hospitality marketing: fantasy, feeling and fun. International Journal of Contemporary Hospitality Management, 18(6), 482-495.

Williams, K., \& Harvey, D. (2001). Transcendent experience in forest environments. Journal of Environmental Psychology, 21(3), 249-260.

Willson, G. (2008). Conceptualizing spirituality in the context of tourism. Paper presented at the Proceedings of the 2 nd international colloquium on tourism and leisure (ICTL), (p. 53), Chiang Mai, Thailand.

Wolf, I. D., \& Croft, D. B. (2010). Minimizing disturbance to wildlife by tourists approaching on foot or in a car: A study of kangaroos in the Australian rangelands. Applied Animal Behaviour Science, 126(1-2), 75-84.

Wolf, I. D., \& Croft, D. B. (2012). Observation techniques that minimize impacts on wildlife and maximize visitor satisfaction in night-time tours. Tourism Management Perspectives, 4(0), 164-175.

Wolf, I. D., Stricker, H. K., \& Hagenloh, G. (2015). Outcome-focussed national park experience management: transforming participants, promoting social well-being, and fostering place attachment. Journal of Sustainable Tourism, 23, 358-381. doi: 10.1080/09669582.2014.959968

Wolf, I. D., \& Wohlfart, T. (2014). Walking, hiking and running in parks: A multidisciplinary assessment of health and well-being benefits. Landscape and Urban Planning, 130, 89-103.

Yearley, L. H. (1990). Mencius and Aquinas: Theories of virtue and conceptions of courage (Vol. 2). Albany, NY: SUNY Press.

Zavitz, K. J., \& Butz, D. (2011). Not That Alternative: Short-term Volunteer Tourism at an Organic Farming Project in Costa Rica. ACME. An Internationalf-Journal for Critical Geographies, 10(3), 412-441. 
Table 1. Characteristics of transformative travellers.

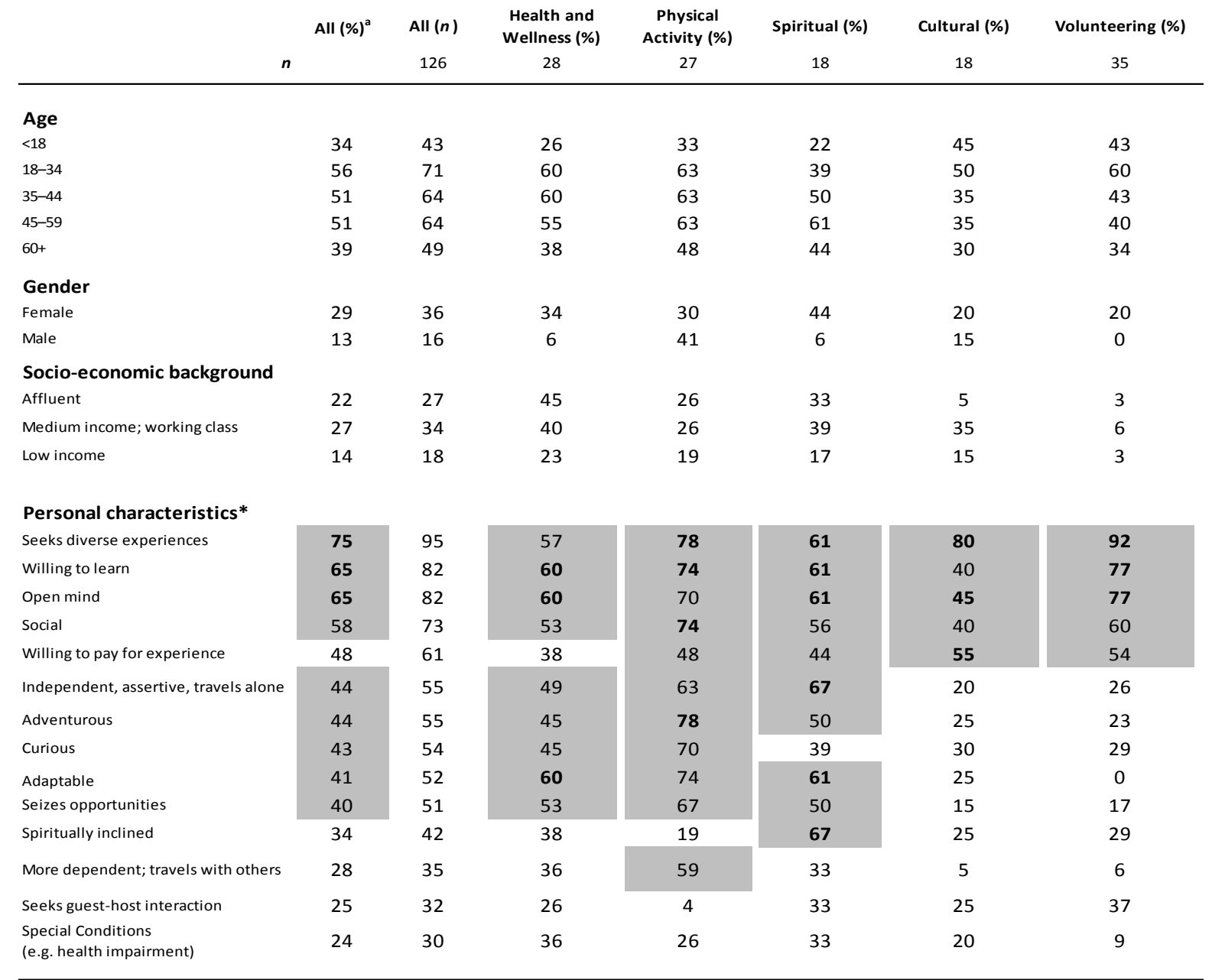

* Marked in (light) grey are participant characteristics that are mentioned in $>40 \%(>20 \%)$ of the reviewed articles. Marked in bold are the top three column-percentages.

${ }^{a}$ The "All"-percentages do not add up to $100 \%$ : some categories such as gender are discussed in less than $100 \%$ of papers (typically they are reported if there is a bias) or multiple categories of a visitor trait are specified in the same article. Interpretation of percentages: for example, $39 \%$ of all reviewed articles specified seniors (60+) as one age group to participate in transformative travel, and $38 \%$ of health and wellness articles did so. In some of the reviewed articles age $(n=30)$, gender bias $(n=73)$, income levels $(n=76)$, and other personal characteristics of participants $(n=9)$ were not specified. 
Table 2. Motivations of transformative travellers.

\begin{tabular}{|c|c|c|c|c|c|c|c|}
\hline$n$ & All (\%) & $\begin{array}{c}\text { All }(n) \\
126\end{array}$ & $\begin{array}{c}\text { Health and } \\
\text { Wellness (\%) } \\
28\end{array}$ & $\begin{array}{c}\text { Physical } \\
\text { Activity (\%) } \\
27\end{array}$ & $\begin{array}{c}\text { Spiritual (\%) } \\
18\end{array}$ & $\begin{array}{c}\text { Cultural (\%) } \\
18\end{array}$ & $\begin{array}{c}\text { Volunteering (\%) } \\
35\end{array}$ \\
\hline Wellbeing & 61 & 76 & 85 & 67 & 89 & 40 & 32 \\
\hline Relaxation & 48 & 61 & 79 & 44 & 78 & 45 & 14 \\
\hline Stress/reduction & 49 & 62 & 72 & 52 & 89 & 30 & 19 \\
\hline Nature/scenery & 53 & 67 & 68 & 56 & 72 & 35 & 38 \\
\hline Health/fitness & 43 & 54 & 66 & 56 & 67 & 25 & 11 \\
\hline Travel/escape/adventure & 55 & 69 & 55 & 56 & 61 & 50 & 54 \\
\hline New experiences & 57 & 72 & 55 & 56 & 61 & 65 & 54 \\
\hline Personal development & 62 & 78 & 55 & 67 & 83 & 30 & 70 \\
\hline Enjoyment/excitement & 66 & 84 & 49 & 67 & 50 & 70 & 87 \\
\hline Exploration & 42 & 53 & 47 & 56 & 44 & 30 & 32 \\
\hline Meditation/spiritual development & 30 & 37 & 47 & 11 & 72 & 20 & 14 \\
\hline Authentic experiences & 43 & 54 & 41 & 38 & 50 & 60 & 35 \\
\hline Social networking & 40 & 50 & 38 & 48 & 45 & 25 & 41 \\
\hline New skills & 42 & 53 & 36 & 52 & 50 & 20 & 46 \\
\hline Risk/challenge & 39 & 49 & 32 & 63 & 45 & 15 & 35 \\
\hline Family time & 21 & 26 & 32 & 26 & 22 & 25 & 5 \\
\hline Cultural experience & 39 & 50 & 28 & 26 & 44 & 65 & 43 \\
\hline Conservation/learning about nature & 31 & 39 & 23 & 33 & 28 & 25 & 41 \\
\hline Beauty/Pampering & 13 & 16 & 21 & 15 & 22 & 10 & 0 \\
\hline Encouraged by others & 18 & 23 & 19 & 33 & 28 & 0 & 11 \\
\hline Religious purpose & 15 & 18 & 17 & 15 & 33 & 10 & 5 \\
\hline Share knowledge with others & 16 & 20 & 15 & 19 & 28 & 0 & 16 \\
\hline Programme was recommended & 10 & 13 & 15 & 11 & 28 & 0 & 3 \\
\hline Identifies with mission & 10 & 13 & 11 & 0 & 22 & 5 & 14 \\
\hline Self-recognition & 12 & 15 & 9 & 26 & 11 & 5 & 8 \\
\hline Referral by a health professional & 2 & 3 & 7 & 4 & 0 & 0 & 0 \\
\hline Membership & 11 & 13 & 6 & 11 & 17 & 5 & 14 \\
\hline Altruism/spirit of service & 32 & 41 & 6 & 11 & 6 & 30 & 84 \\
\hline Programme incentives & 6 & 7 & 6 & 0 & 6 & 5 & 11 \\
\hline Scientific research & 7 & 9 & 4 & 4 & 11 & 0 & 14 \\
\hline Humanitarian Purpose & 18 & 23 & 4 & 0 & 6 & 15 & 51 \\
\hline Professional development & 15 & 19 & 0 & 11 & 11 & 20 & 30 \\
\hline Legacy- leaving one & 2 & 3 & 0 & 0 & 0 & 0 & 8 \\
\hline Legacy - familial heritage & 2 & 3 & 0 & 0 & 6 & 10 & 0 \\
\hline
\end{tabular}

Note: Marked in dark (light) grey are participant motivations that are mentioned in $>40 \%(>20 \%)$ of the reviewed articles. Marked in bold are the top three column-percentages. Interpretation of percentages: for example, $21 \%$ of all reviewed articles specified family time as one motivation to participate in transformative travel, and $85 \%$ of all health and wellness articles specified wellbeing as one motivation. Motivations were not specified in 12 of the reviewed articles. 
Table 3. Benefits attained by transformative travellers.

\begin{tabular}{|c|c|c|c|c|c|c|c|c|}
\hline & & All (\%) & All $(n)$ & $\begin{array}{l}\text { Health and } \\
\text { Wellness (\%) }\end{array}$ & $\begin{array}{c}\text { Physical } \\
\text { Activity (\%) }\end{array}$ & Spiritual (\%) & Cultural (\%) & Volunteering (\%) \\
\hline Benefit classification & Individual benefits & $n$ & 126 & 28 & 27 & 18 & 18 & 35 \\
\hline Health Wellbeing & Psycholog. Wellbeing & 72 & 90 & 79 & 89 & 89 & 40 & 60 \\
\hline Health Wellbeing & Emotional Wellbeing & 64 & 80 & 58 & 85 & 83 & 40 & 54 \\
\hline Personal Competence & Independence & 57 & 72 & 38 & 63 & 33 & 65 & 77 \\
\hline Environmental & Appreciation & 55 & 70 & 49 & 74 & 61 & 45 & 49 \\
\hline Personal Competence & Self Enrichment & 55 & 69 & 62 & 56 & 56 & 55 & 49 \\
\hline Health, wellbeing & Physical health & 50 & 63 & 72 & 78 & 72 & 25 & 11 \\
\hline Socio-cultural relationships & Social & 44 & 55 & 38 & 67 & 50 & 25 & 37 \\
\hline Additional benefits & Sense of achievement & 43 & 54 & 40 & 63 & 50 & 5 & 46 \\
\hline Socio-cultural relationships & Cultural & 38 & 48 & 19 & 37 & 11 & 60 & 57 \\
\hline Environmental & Awareness, sensitivity & 37 & 47 & 40 & 63 & 50 & 10 & 23 \\
\hline Additional benefits & Repeated participation & 36 & 46 & 40 & 59 & 39 & 20 & 23 \\
\hline Health, wellbeing & Spirituality & 32 & 40 & 45 & 19 & 78 & 15 & 17 \\
\hline Economic & In general & 30 & 38 & 28 & 7 & 17 & 45 & 49 \\
\hline Personal competence & Career/personal skills & 28 & 36 & 21 & 52 & 22 & 5 & 32 \\
\hline Additional benefits & Encouraging others & 26 & 33 & 23 & 41 & 28 & 20 & 20 \\
\hline Behavioural change & Health and lifestyle & 21 & 27 & 38 & 19 & 44 & 5 & 6 \\
\hline Socio-cultural relationships & Solidarity, teamwork & 19 & 24 & 11 & 33 & 6 & 20 & 20 \\
\hline Behavioural Change & Any & 18 & 23 & 28 & 19 & 17 & 10 & 14 \\
\hline Socio-cultural relationships & Good citizenship & 17 & 21 & 15 & 7 & 6 & 32 & 23 \\
\hline Socio-cultural relationships & Recognition & 15 & 19 & 11 & 37 & 11 & 0 & 11 \\
\hline Behavioural change & Responsibility & 13 & 16 & 23 & 11 & 11 & 10 & 9 \\
\hline Environmental & Conservation & 9 & 12 & 6 & 4 & 6 & 5 & 20 \\
\hline Behavioural change & Sustainability & 6 & 8 & 6 & 7 & 6 & 5 & 6 \\
\hline Behavioural change & Social & 6 & 8 & 6 & 7 & 0 & 10 & 6 \\
\hline Behavioural change & Purchasing & 4 & 4 & 2 & 0 & 0 & 10 & 6 \\
\hline Behavioural change & Donating time/money & 3 & 4 & 4 & 0 & 0 & 5 & 6 \\
\hline Programme-specific & Incentives & 3 & 4 & 0 & 0 & 0 & 10 & 6 \\
\hline Behavioural change & Voting political action & 2 & 2 & 0 & 0 & 0 & 0 & 6 \\
\hline
\end{tabular}

Note: Marked in dark (light) grey are participant benefits that are mentioned in $>40 \%$ (>20\%) of the reviewed articles. Marked in bold are the top three columnpercentages. Interpretation of percentages: for example, $72 \%$ of all reviewed articles specified psychological wellbeing as one benefit attainable from transformative travel, and $79 \%$ of all health and wellness articles specified psychological wellbeing as one benefit. 
Table 4. Experiential factors that transform participants in transformative travel. For example various types of immersion played an important role across all travel typologies while regular/repeated participation was particularly important for facilitating transformation in nature-based physical activity and spiritual travel.

\begin{tabular}{|c|c|c|c|c|c|c|c|c|}
\hline & & All (\%) & All $(n)$ & $\begin{array}{c}\text { Health and } \\
\text { Wellness }^{\mathrm{a}}(\%)\end{array}$ & $\begin{array}{c}\text { Physical } \\
\text { Activity (\%) }\end{array}$ & Spiritual (\%) & Cultural (\%) & $\begin{array}{c}\text { Volunteering } \\
(\%)\end{array}$ \\
\hline $\begin{array}{l}\text { Experience trait } \\
\text { classification }\end{array}$ & Individual experience traits & $n$ & 126 & 28 & 27 & 18 & 18 & 35 \\
\hline Environment & Natural & 72 & 90 & 72 & 100 & 72 & 50 & 60 \\
\hline Immersion & Immersive (nsp.) & 67 & 85 & 66 & 78 & 78 & 65 & 57 \\
\hline Immersion & Social & 66 & 83 & 45 & 82 & 39 & 60 & 87 \\
\hline Reconnection & With Oneself & 60 & 76 & 70 & 85 & 78 & 40 & 35 \\
\hline Immersion & Participatory & 62 & 79 & 51 & 52 & 61 & 50 & 87 \\
\hline Challenge & Mental & 56 & 71 & 64 & 85 & 56 & 15 & 49 \\
\hline Activities & Escape & 54 & 68 & 68 & 70 & 83 & 50 & 16 \\
\hline Challenge & Physical & 55 & 69 & 55 & 96 & 50 & 20 & 43 \\
\hline Activities & Regular/repeated participation & 53 & 67 & 53 & 74 & 72 & 25 & 41 \\
\hline Challenge & Environment & 53 & 66 & 53 & 85 & 39 & 30 & 46 \\
\hline Immersion & Cultural & 54 & 68 & 38 & 33 & 33 & 85 & 76 \\
\hline Immersion & Active & 54 & 68 & 17 & 74 & 22 & 50 & 87 \\
\hline Challenge & Emotional & 46 & 58 & 60 & 82 & 50 & 25 & 16 \\
\hline Environment & Rural & 45 & 57 & 51 & 74 & 61 & 45 & 11 \\
\hline Reconnection & With the land and heritage & 41 & 51 & 47 & 70 & 44 & 30 & 16 \\
\hline Environment & Foreign & 40 & 50 & 34 & 22 & 28 & 50 & 60 \\
\hline Activities & Authentic & 36 & 45 & 42 & 41 & 45 & 60 & 11 \\
\hline Immersion & Interactive & 40 & 50 & 13 & 19 & 22 & 50 & 81 \\
\hline Immersion & Active and passive components & 25 & 32 & 49 & 26 & 50 & 5 & 3 \\
\hline Activities & Ecotourism sustainable practices & 25 & 32 & 28 & 11 & 28 & 30 & 30 \\
\hline Environment & Urban & 24 & 31 & 21 & 19 & 6 & 20 & 43 \\
\hline Activities & Gastronomy & 21 & 26 & 38 & 15 & 29 & 25 & 5 \\
\hline Reconnection & With family & 20 & 25 & 26 & 33 & 22 & 15 & 5 \\
\hline Immersion & Acculturation & 16 & 20 & 9 & 19 & 17 & 10 & 22 \\
\hline Activities & Events and festivals & 13 & 16 & 13 & 11 & 17 & 25 & 5 \\
\hline Immersion & Passive & 8 & 10 & 4 & 0 & 11 & 30 & 5 \\
\hline
\end{tabular}

Note: Marked in dark (light) grey are participant benefits that are mentioned in $>40 \%(>20 \%)$ of the reviewed articles. Marked in bold are the top three column percentages. Per default $(=100 \%)$ physical activity was reviewed only in the context of nature and therefore not highlighted. Interpretation of percentages: for example, $72 \%$ of all

reviewed articles specified the natural environment as one experience factor that facilitates transformation in travel, and $45 \%$ of all health and wellness articles specified social immersion as one transformative experience factor. Experience factors were not specified in four of the reviewed articles. 
Figure 1. Transformative travel framework depicting the inter-relationships between participant and experience characteristics that trigger a transformation process (Mezirow, 1991), and the experience benefits to be attained by participants, as well as outcomes for parks such as participant satisfaction and destination loyalty. Other experience features and benefits are listed that were reported in at least $40 \%$ of publications within one or more of the five reviewed travel typologies, as presented in more detail in Figure 2. Their listed order reflects how commonly they were reported across all travel typologies. For example, psychological well-being was the most commonly reported health and wellbeing benefit when all travel typologies were pooled. A quantitative summary of how the frequency of reported participant characteristics, experience characteristics and experience benefits varies with travel typology is shown in Figure 2. For a definition of 'signature strengths' like willingness to learn, open-mindedness, curiosity and adaptability refer to Section 3.1.

Transformation Triggers

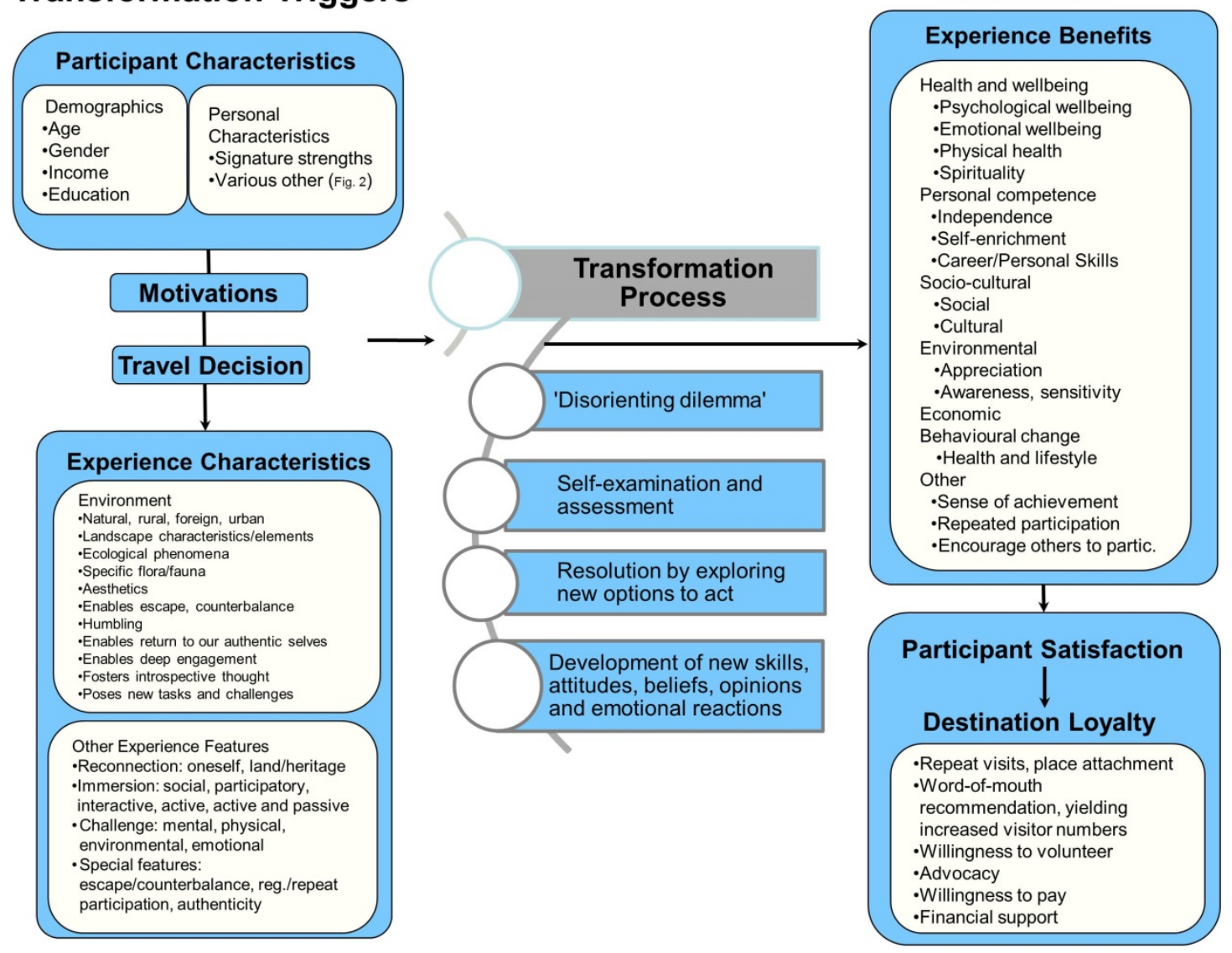


Figure 2. Model of transformative travel market niches for protected areas showing associated experience-outcome relationships, according to the most commonly noted participant characteristics (age, gender, income), participant motivations and experience characteristics linked to benefits. Listed are qualities of model components if noted in at least approximately $40 \%$ of publications reviewed within a travel typology, a subjective measure of their importance (actual percentages are given in brackets).

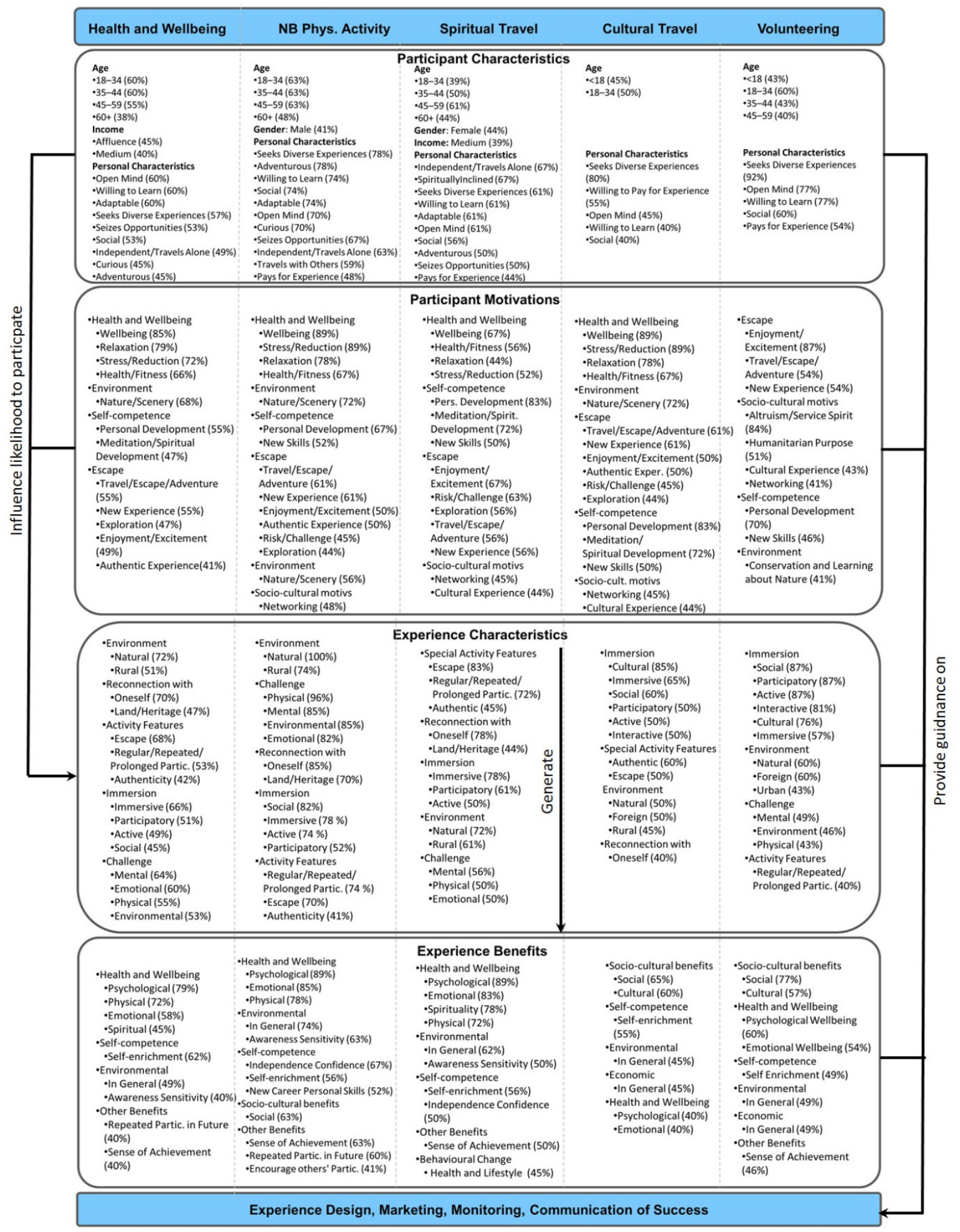


i A term originally from India meaning a spiritual hermitage or studio typically with activities such as contemplation, yoga, music study or religious study.

\section{Acknowledgements}

We gratefully acknowledge the very insightful comments and support of Bernard Lane (Founding Editor), and the anonymous reviewers in improving earlier versions of this paper. The authors further thank Christine Alimane and Tahnee Bainbridge for their assistance in data collection and coding. This work was supported by the Customer Experience Division of the NSW National Parks and Wildlife Service, NSW Office of Environment and Heritage. 